\title{
$\therefore$ Phytochemistry of Amaranthus viridis: GC-MS Analysis
}

\section{IJCRR}

Section: Healthcare

ISI Impact Factor

(2019-20): 1.628

IC Value (2019): 90.81

SJIF (2020) $=7.893$

\section{Varalakshmi Thanikachalam, Indira A. Jayaraj}

Department of Biochemistry, Kongunadu Arts and Science College, Coimbatore, Tamil Nadu, India.

\section{ABSTRACT}

Introduction: Amaranth is a very versatile crop that is grown in a wide range of agro-climatic conditions; it resists drought, heat, and pests, and adapts readily to new environments with nutraceutical potentials. The herb was consumed as a leafy vegetable in various parts of India as a cheap and nutritive source of food materials in low economic society. Amaranthus Viridis(Amaranthaceae) widely distributed all over the world, growing under a wide range of climatic conditions and has been utilized as a medicinal herb in traditional Ayurveda medicine for the treatment of inflammation, ulcer, diabetes, asthma and hyperlipidemia.

Objective: The present research focused on evaluate the antioxidant and biological properties of Amaranthus Viridis.

Methods: The phytochemical compositions of the extract of leaves were studied using gas chromatography-mass spectroscopy. Gas chromatography-mass spectroscopy (GC-MS), a hyphenated system which is a very compatible technique and the most commonly used technique for the identification and quantification purpose was used.

Results: The GC-MS Analysis revealed 40 constituents of which many of the compounds were identified. The active principles with their retention time (RT), molecular weight (MW) and concentration (\%) of the corresponding compounds were observed in the leaf extract. GC-MS chromatogram of the leaf extract of $A$. viridis belonging to the family Amaranthaceae showed 40 peaks which indicate the presence of forty compounds.

Conclusion: The current study suggests that the plant have a potent therapeutic activity and paves the way for the development of several treatment regimens based on compounds from this extract.

Key Words: Amaranthus Viridis, Ayurveda, Inflammation, Antioxidant, Treatment, Chromatography

\section{INTRODUCTION}

The world is endowed with a rich diversity of medicinal plants. About $80 \%$ of the world's population uses herbs for medicinal purposes. Herbs have always been the principal form of medicine in the world. Some biologically active compounds isolated from herbs have been explored for the inhibition of the growth of pathogenic microbes because of their antimicrobial potential. ${ }^{1}$ The medicinal value and multiple biological properties of several plants are defined by their phytochemical constituents. ${ }^{2}$

Plants have provided a source of inspiration for novel drug compounds, ${ }^{3}$ as plant-derived medicines made large contributions to human health and well-being. Plant-derived medicines are widely used because they are relatively safer than synthetic alternatives, as they are easily available and cheaper. ${ }^{4}$ Many plant species have been evaluated for their antimicrobial activity in the past 20 years. ${ }^{5}$

They provide us with the key chemical structure for the development of new phytomedicine to be used for the treatment of disease. The active principles of many drugs found in plants are recognized as secondary metabolites. ${ }^{6}$ Amaranthus, commonly known as Green amaranth, is a multinational genus of herbs. In the last decade, amaranth is not only used in the common diet but also in the diet of people with celiac disease or allergies to typical cereals. ${ }^{?}$

Recently drug resistance to a human pathogenic organism has been reported worldwide. Medicinal plants are an expensive gift from nature as they are the sources of important

\section{Corresponding Author:}

Varalakshmi Thanikachalam, Department of Biochemistry, Kongunadu Arts and Science College, Coimbatore, Tamil Nadu, India. Phone: 9791197355; Email: varalakshmi.th@gmail.com

ISSN: 2231-2196 (Print)

Received: 06.09.2020
ISSN: 0975-5241 (Online)

Revised: 13.11 .2020
Accepted: 28.12 .2020
Published: 12.04.2021 
therapeutic aids for alleviating human ailments. Gas Chromatography-Mass Spectrometry (GC-MS) is the best technique to identify the bioactive constituents of long-chain hydrocarbons, alcohols, acids, esters, alkaloids, steroids, amino acid and nitro compounds. ${ }^{8-11}$ Therefore, characterization of extracts of medicinal plants is necessary due to its numerous benefits to science and society. Nevertheless, Amaranthus has received notably less research attention as vegetables than grain amaranths.

Hence, the present study was aimed at determining phytochemical constituents with the aid of the GC-MS technique and in vitro screening of pure extract of leaves from locally grown Amaranthus Viridis plants for their phytochemical study. The findings of this study provide important data on the bioactive substances of this underutilized vegetable, and thereby promoting their utilization in the food industry.

\section{MATERIALS AND METHODS}

\section{Collection of samples}

Fresh plant leaves of Amaranthus Viridis was collected and authenticated by Prof.P.Jayaraman, Director, Plant Anatomy Research Centre, Chennai, Tamil Nadu, and India. A voucher specimen (Reg.No. PARC/2019/4054). The leaves were thoroughly washed through tap water and dried under shade for 3-5 days. The dried leaves were ground to a fine powder and stored in bags for further use.

\section{Preparation of extracts}

50 grams of dried powder of Amaranthus Viridis leaves were packed in a separate round bottom flask for sample extraction using $500 \mathrm{ml}$ water. The extraction was conducted with $20 \mathrm{ml}$ of water for 24 hours. At the end of the extraction, the crude extract was stored in refrigerator. ${ }^{12}$

\section{Chemicals and reagents}

All chemicals and reagents were procured from certified suppliers and were of the highest analytical standard.

\section{Gas Chromatography-Mass Spectroscopy}

Gas chromatography-mass spectroscopy (GC-MS), a hyphenated system which is a very compatible technique and the most commonly used technique for the identification and quantification purpose was used. The unknown organic compounds in the complex mixture can be determined by interpretation and also by matching the spectra with reference spectra.

\section{Preparation of extract}

The extract of the leaves was analyzed using Gas Chromatography Mass Spectroscopy for the identification of the phyto- chemical compounds present. A solvent blank analysis was first conducted using $1 \mu \mathrm{l}$ of absolute ethanol. ${ }^{13}$ Then $1 \mu \mathrm{l}$ of the reconstituted extract solution was employed for GC-MS analysis as previously described with modifications. ${ }^{14}$

\section{Procedure}

\section{Identification of bioactive compounds by GCMS}

The purified extract fractions were individually examined using GC SHIMADZU QP2010 system and gas chromatograph interfaced to a mass spectrometer equipped with Elite-1 fused silica capillary column. For GC-MS detection, an electron ionization energy system with ionization energy of $70 \mathrm{eV}$ was used. Helium was used as carrier gas at a constant flow rate of $1 \mathrm{ml} / \mathrm{min}$ and an injection volume of $2 \mu 1$ was employed.

The sample was run for 40 minutes with a solvent out time of 9.50 minutes. Mass spectra were taken with a scan-interval of 0.6 seconds. Interpretation of the mass spectrum was achieved by using the database for different bioactive compounds.

GCMS analysis of bioactive compounds from the sample The leaf extract was subjected to Gas Chromatography and Mass Spectroscopy for the determination of bioactive volatile compounds.

\section{Identification of phytoconstituents}

Interpretation of the mass spectrum of GC-MS was done using the database of National Institute Standard and Technology (NIST) having more than 62,000 patterns. ${ }^{15},{ }^{16} \mathrm{NIST}$ library was used to calculate the mass spectrum. Quantitative determination was made by respective peak areas to TIC areas from the GC-MS. The principle name, molecular weight, retention time and peak area percentage of the test materials was ascertained. The column temperature was programmed from $75-260^{\circ} \mathrm{C}\left(\right.$ rate $\left.=6^{\circ} \mathrm{C} / \mathrm{min}\right)$ with the lower and upper temperatures being held for 3 and 10 minutes respectively.

Total GC running time was $43.2 \mathrm{~min}$. The GC injector and MS transfer line temperatures were set at $280^{\circ} \mathrm{C}$ and $290^{\circ} \mathrm{C}$ respectively. All analysis was done in the split-less mode.

Helium $(99.9 \%$ ) was used as a carrier gas (flow rate $=1.0 \mathrm{ml} /$ min) and an injection volume of one $\mu l$ was used for analysis. Major and essential compounds were identified by their retention times and mass fragmentation patterns.

\section{RESULTS}

Phenolic compounds can be defined as a large series of chemical constituents possessing at least one aromatic ring, bearing hydroxyl and other sub-constituents. GC- MS analysis is the most used method for the identification of plant phenolic 
compounds. Amaranthus Viridis leaf extracts are found to be a vital source of useful bioactive substances. These bioactive compounds are involved in various biological functions such as communication, infection, reproduction and self- defence. In the present study, we have identified bioactive compounds present in the extract fraction of leaf by GC-MS analysis and summarized in Table 1. The active principles with their retention time (RT), molecular weight (MW) and concentration (\%) of the corresponding compounds were observed in the leaf extract. GC-MS chromatogram of the leaf extract of A. Viridis belonging to the family Amaranthaceae showed 40 peaks which indicate the presence of forty compounds. The spectra of the compounds were matched with Wiley 9.0 and the National Institute of Standards and Technology libraries. The compounds detected are presented in Table 1

\section{DISCUSSION}

The plants contain large amounts of secondary metabolites that exert a wide range of biological activities on physiological systems. It was also reported that the activities of some plant constituents with compound nature of alkaloids, flavonoids, palmitic acid (hexadecanoic acid, ethyl ester and n-hexadecanoic acid, unsaturated fatty acid and linolenic (docosatetraenoic acid and octadecatrienoic acid) as antimicrobial, antioxidant, anti-inflammatory, hypocholesterolemic, cancer preventive, hepatoprotective, antiarthritic, antihistaminic, antieczemic, immunomodulatory and anticoronary. ${ }^{17}$

Secondary metabolites of the plants attract beneficially and repel harmful organisms, serve as phytoprotectants and respond to environmental changes. In general, the phytochemical contents (Table 1) were by the previous reports for some of the vegetables. These phytocompounds are responsible for various pharmacological actions of the leaves of the plant.

Benzoic acid, 2-[(trimethylsilyl)oxy]-, trimethylsilyl ester $(24.09 \%)$ is found as the major compound and forty nine minor compounds such as Nonamethyl, Phenyl-, Cyclopentasiloxane $(6.10 \%),(+,-)-3$.beta.-(acetyloxy)-3-ethynyl-1,2,3,4,4a. beta.,12a. (5.67\%), [Bis (trimethylsilyl) methyl] diphenyl phosphine \$\$ Phosphine (5.59\%), Benzoic acid, 2-[(trimethylsilyl) oxy]-, trimethylsilyl ester (5.32\%), 1,2-Diphenyl tetramethyldisilane \$ Disilane,1,1,2,2-tetramethyl-1,2-diphenyl (4.98\%), Benzophenone, 2-(trimethylsiloxy)- (CAS) Trimethylsilyl ether of O-hydroxybenzophenone $(3.50 \%)$, 7-(P-Chlorophenyl)imino-6-(P-tolyl)-1,3-dimethyl-2,4 dioxo-1,2,3,4,6,7- hexahydro pyramid [4,5-d] pyramidine (3.14\%), 4-.alpha.,20-dimethyl-3-.beta.-dimethyl-.. (2.84\%), Silane, [1,3,5-benzenetriyltris (oxy)] tris [trimethyl- (CAS) Phloroglucinol tris MS (2.76\%), 2-Isopropyl phenol- Trimethylsilyl- Ether (2.73\%), 4H-1-Benzopyran-4-one, 2-(2,6-dimethoxyphenyl)- 5,6-dimethoxy- (CAS) Zapotin \$\$
Flavone (2.46\%), (Z)-1-[(1',1'-dimethylethyl) diphenylsilyl]3-trimethylsilyloxyprop-1-ene (2.37\%), Prosta-5,10,13trien-1-oic acid, 15-[[(1,1-dimethylethyl) dimethyl ethylsily] oxy]-9-oxo- (2.19\%), Silane, trimethyl (triphenylethenyl)$\$ \$(2.18 \%)$ and the remaining compounds peak area ranged from $1.84 \%$ to $0.16 \%$

The results from the current study indicate that methanol leaf extract of the Amaranthus Viridis tested by GC-MS analysis contained various types of compounds with potential pharmacological activity. The presence of various bioactive compounds justifies the use of Amaranthusviridisfor various ailments by traditional practitioners. From GC-MS data, identification of more compounds in their extract and it previously reported that these compounds have antibacterial, antifungal, antioxidant and anticancer activity but further researches should be made to isolate and purification of natural products in their extract.

\section{CONCLUSION}

The edible plant species Amaranthus viridis from the underutilized plant family had a rich amount of valuable ingredients that are beneficial for health. Further research work is required in more details about in vitro and in vivo investigations to establish which components of the extract are biologically active in terms of activity. The isolation of components from this readily available plant resource and its utilization as natural agents could be of high economic value. Hence, the identified plant components using GC-MS can be used as a tool for the identification of adulterants. The current pioneering study suggests that the extract is a potent therapeutic agent. It paves the way for the development of several treatment regimens based on this extract. Also, further research is necessary to identify and purify the active compounds responsible for therapeutic activity, as well as the unidentified compounds.

\section{ACKNOWLEDGEMENT}

We are thankful to the Department of Biochemistry, Kongunadu College, Coimbatore, Tamil Nadu, and India for providing facilities to carry out research work. The authors acknowledge the immense help received from the scholars whose articles are cited and included in references to this manuscript. The authors are also grateful to authors/ editors/publishers of all those articles, journals and books from where the literature for this article has been reviewed and discussed

Conflict of Interest: Authors declare no conflict of interest. Source of Funding: None 


\section{REFERENCES}

1. Abukakar MA, Ukwuani AN, Shehu RA. Phytochemical screening and antibacterial activity of Tamarindus indica pulp extract. J Biochem 2008;11(2):134-138.

2. Fallah HSM, Alavian HR, Heydari MR, Abolmaali K. The Efficacy of Liv-52 on Liver Cirrhotic Patients: A Randomized, Double-Blind, Placebo-Controlled First Approach. J Phytomed 2005;12:619-624.

3. Velayutharaj A, Muthumani L, Senthilnathan R, Rajendran SM, Shivakumar R, Saraswathi R. Significance of Secreted Frizzled Related Protein 4 (SFRP4) in Type 2 Diabetic and non-Diabetic Subjects in the Rural Agricultural Population Who are Exposed to Pesticides for the Prediction of Diabetes Mellitus. Int J Curr Res Rev 2018;10(06):7-9.

4. Iwu MM, Duncan AR, Okunji CO. New Antimicrobials of Plant Origin. Int J Janick Ed 1999;1:11.

5. Castello MC, Anita P, Naresh C, Madhuri S.Antimicrobial Activity of Crude Extracts from Plant Parts and Corresponding Calli of Bixaorellina. Indian J Exp Biotechnol 2002;40:13781381.

6. Ghani A. Introduction to Pharmacognosy. Ahmadu Bello University Press, Nigeria. 1990.

7. Dobelis IN. Magic and Medicine of Plants. The Readers Digest Association Inc., 1993.

8. Subramanian S, Ramakrishnan N. Chromatographic fingerprint analysis of Naringi crenulata by HPTLC technique. Asian Pac J Trop Biomed 2011;1:195-198.

9. Muthulakshmi A, Joshibhi-Margret R, Mohan VR. GC-MS analysis of bioactive components of Feronia elephant Correa (Rutaceae). J Appl Pharm Sci 2012;1:69-74.
10. Yamunadevi M, Wesely EG, Johnson M. Chromatographic fingerprint analysis of steroids in Aerva Lanasa L. by HPTLC technique. Asian Pac J Trop Biomed 2011;1:428-433.

11. Gopalakrishnan S, Vadivel E. GC-MS Analysis of some bioactive constituents of Mussaenda frondosa Linn. Int J Pharm Biosci 2011;2:313-320.

12. Paranthaman R, Praveen K, Kumaravel S. GC-MS Analysis of Phytochemicalsand Simultaneous Determination of Flavonoids in Amaranthus caudatus (Sirukeerai) by RP-HPLC. J Anal Bioanal Tec 2012;1:14.

13. Komansilan A, Abadi A, Yanuwiadi B, Kaligis DA. Isolation and Identification ofBiolarvicide from Soursop (Annona muricata Linn) Seeds to Mosquito (Aedesaegypti) Larvae. Int J Engi Technol 2012;12(03):28-32.

14. Kumar PP, Kumaravel S, Lalitha C. Screening of antioxidant activity, total phenolics and GC-MS study of Vitex negundo. Afr J Biochem 2010;4:191-195.

15. Akubugwo IE, Obasi NA, Chinyere AE. Nutritional and chemical value of Amaranthus hybrid slaves from Afikpo Nigeria. Afr J Biotechnol 2007;6:2833-2839.

16. Akubugwo IE, Obasi AA, Chinyer GC, Ugbogu AE. Mineral and phytochemical contents in leaves of Amaranthus hybridus L and Solanum nigrumL. Subjected to different processing methods. Afr J Biochem Res 2008;8:40-44.

17. Rodrigues E, Tabach R, Galduróz JCF, Negri G. Plants with possible anxiolytic and/or hypnotic effects indicated by three Brazilian cultures - Indians, Afro-Brazilians, and river-dwellers. Stud Nat Prod Chem 2008;35:549-595.

\section{Table 1: Phytocomponents identified in the leaf extract of Amaranthus viridis by GC-MS analysis}

\begin{tabular}{|c|c|c|c|c|c|}
\hline S No & RT & Name of the compound & Molecular formula & MW & Peak Area \\
\hline 1 & 7.183 & Cyclononasiloxane, octadecamethyl- $\$ \$$ & $\mathrm{C}_{18} \mathrm{H}_{54} \mathrm{O}_{9} \mathrm{Si}_{9}$ & 666 & 0.33 \\
\hline 2 & $7 \cdot 425$ & $\begin{array}{l}\text { Dodecamethylcyclohexasiloxane \$ - A cyclic volatile methylsilox- } \\
\text { ane (cVMS) used in cosmetic and personal care products. }\end{array}$ & $\mathrm{C}_{12} \mathrm{H}_{36} \mathrm{O}_{6} \mathrm{Si}_{6}$ & 444 & 0.25 \\
\hline 2 & 7.608 & $\begin{array}{l}\text { Monensin, methyl ester (CAS) Monensin methyl ester } \$ \$ \\
\text { 1,6-Dioxaspiro[4.5]decane-7-butyric acid, 2-[5-ethyltet- } \\
\text { rahydro-5-[tetrahydro-3-methyl-5-[tetrahydro-6-hydroxy- } \\
\text { 6-(hydroxymethyl }\end{array}$ & $\mathrm{C}_{37} \mathrm{H}_{64} \mathrm{O}_{11}$ & 684 & 0.32 \\
\hline 4 & $7 \cdot 748$ & $\begin{array}{l}\text { 3,3,5-Tributoxy-1,1,1,7,7,7-hexamethyl-5-(trimethylsiloxy)tetrasi- } \\
\text { loxane } \$ \$\end{array}$ & $\mathrm{C}_{21} \mathrm{H}_{54} \mathrm{O}_{7} \mathrm{Si}_{5}$ & 558 & 0.23 \\
\hline 5 & 8.597 & Tetradecamethylcycloheptasiloxane \$\$ & $\mathrm{C}_{14} \mathrm{H}_{42} \mathrm{O}_{7} \mathrm{Si}_{7}$ & 518 & 0.21 \\
\hline 6 & 9.617 & $\begin{array}{l}\text { L-Threonine, N-[(2,4-dichlorophenoxy)acetyl]- \$ N.alpha.-(2,4- } \\
\text { D)-L-Threonine } \$ \$\end{array}$ & $\mathrm{C}_{12} \mathrm{H}_{13} \mathrm{C}_{12} \mathrm{NO}_{5}$ & 321 & 0.16 \\
\hline 7 & 9.933 & Dibenz[a,c]cycloheptan-9-amine, 2,3,4-trimethoxy-N-acetyl- \$\$ & $\mathrm{C}_{20} \mathrm{H}_{23} \mathrm{NO}_{4}$ & 341 & 0.18 \\
\hline 8 & 10.075 & $1,1,3,3,5,5,7,7,9,9,11,11,13,13,15,15$-Hexadecamethyl-octasiloxane $\$ \$$ & $\mathrm{C}_{16} \mathrm{H}_{50} \mathrm{O}_{7} \mathrm{Si}_{8}$ & 578 & 0.22 \\
\hline 9 & 11.854 & $\begin{array}{l}\text { Benzoic acid, 2,6-bis[(trimethylsilyl) oxy]-, trimethylsilyl ester } \$ \$ \\
\text { 2,6-Dihydroxybenzoic acid 3TMS \$\$ }\end{array}$ & $\mathrm{C}_{16} \mathrm{H}_{30} \mathrm{O}_{4} \mathrm{Si}_{3}$ & 370 & 0.16 \\
\hline 10 & 12.375 & $\begin{array}{l}\text { 2-Cyclohexen-1-one, 3-methyl-6-(1-methyl ethenyl)- \$ } \$ \text {-Men- } \\
\text { tha-1,8-dien-3-one \$\$ Isopiperitenone \$\$ }\end{array}$ & $\mathrm{C}_{10} \mathrm{H}_{14} \mathrm{O}$ & 150 & 0.16 \\
\hline 11 & 12.970 & $\begin{array}{l}(4 \mathrm{R}, 5 \mathrm{R}, 6 \mathrm{R}, 8 \mathrm{R}, 8 \mathrm{aS}, 12 \mathrm{aS})-5,8,8 \mathrm{a}, 11,12,12 \mathrm{a}-\text { hexahydro-1,4,8-tri- } \\
\text { hydroxy-5-methoxy-9,10,12a-trimethyl-3H-phenanthro[3,2-b] } \\
\text { pyran-2(4H)-one \$\$ }\end{array}$ & $\mathrm{C}_{21} \mathrm{H}_{26} \mathrm{O}_{6}$ & 374 & 0.18 \\
\hline 12 & 13.084 & 4-.alpha.,2o-dimethyl-3-.beta.-dimethyl-... \$\$ & $\mathrm{C}_{29} \mathrm{H}_{54} \mathrm{O}_{2} \mathrm{~S}_{\mathrm{I}}$ & 462 & 0.34 \\
\hline 13 & 13.137 & Acetphenone 4-[1-adamantyl]-3- thiosemicarbazone $\$ \$$ & $\mathrm{C}_{19} \mathrm{H}_{25} \mathrm{~N}_{3} \mathrm{~S}$ & 327 & 0.31 \\
\hline 14 & 13.201 & 3,4-Methylenedioxyphenyllactic acid, di-TMS \$\$ & $\mathrm{C}_{16} \mathrm{H}_{26} \mathrm{O}_{5} \mathrm{Si}_{2}$ & 354 & 0.20 \\
\hline
\end{tabular}


Table 1: (Continued)

\begin{tabular}{|c|c|c|c|c|c|}
\hline S No & RT & Name of the compound & Molecular formula & MW & Peak Area \\
\hline 15 & 13.264 & $\begin{array}{l}\text { Benzoic acid, 3,5-dimethoxy-4-[(trimethylsilyl)oxy]-, trimethyl- } \\
\text { silyl ester (CAS) 4-Hydroxy-3,5-Dimethoxybenzoic Acid-Ditms } \\
\text { Syringic Acid-Ditms \$\$ Trimethylsilyl 3,5 }\end{array}$ & $\mathrm{C}_{15} \mathrm{H}_{26} \mathrm{O}_{5} \mathrm{~S}_{\mathrm{I} 2}$ & 342 & 0.31 \\
\hline 16 & 13.338 & di-3-(1-Phenyl-1-methylethyl)phenyl amine \$\$ & $\mathrm{C}_{30} \mathrm{H}_{31} \mathrm{~N}$ & 405 & 0.46 \\
\hline 17 & 13.467 & 4-.alpha., 20-dimethyl-3-.beta.-dimethyl-... \$\$ & $\mathrm{C}_{29} \mathrm{H}_{54} \mathrm{O}_{2} \mathrm{~S}_{\mathrm{I}}$ & 462 & 1.16 \\
\hline 18 & 13.516 & Silane, trimethyl(triphenylethenyl)- \$\$ & $\mathrm{C}_{23} \mathrm{H}_{24} \mathrm{Si}$ & 328 & 0.58 \\
\hline 19 & 13.567 & Heptamethyl-Phenyl-Cyclotetrasiloxane \$\$ & $\mathrm{C}_{13} \mathrm{H}_{26} \mathrm{O}_{4} \mathrm{~S}_{14}$ & 358 & 0.88 \\
\hline 20 & 13.661 & $\begin{array}{l}\text { Pregnan-20-one, 3-(acetyloxy)-5, 6:16, 17-diepoxy-, (3.beta. } 5 . \\
\text { alpha., 6.alpha., 16.alpha.)- } \$ \text { 5.alpha.-Pregnan-2o-one, 5,6. } \\
\text { alpha.:16.alpha.,17-diepoxy-3.beta.-hydroxy-, acetate } \$ \$\end{array}$ & $\mathrm{C}_{23} \mathrm{H}_{32} \mathrm{O}_{5}$ & 388 & 1.18 \\
\hline 21 & 13.724 & $\begin{array}{l}\text { [5-(3-Methoxymethoxy-10,13-dimethyl-2,3,4,9,10,11,12,13,14,15,16,17- } \\
\text { dodecahydro-1H-cyclopenta[a]phenanthren-17-yl)-hex-1-ynyl]- } \\
\text { trime } \$ \$\end{array}$ & $\mathrm{C}_{30} \mathrm{H}_{48} \mathrm{O}_{2} \mathrm{Si}$ & 468 & 1.11 \\
\hline 22 & 13.975 & $\begin{array}{l}\text { 7-(P-Chlorophenyl)imino-6-(P-tolyl)-1,3-dimethyl-2,4- } \\
\text { dioxo-1,2,3,4,6,7-hexahydro pyrimido [4,5-d] pyrimidine } \$ \$ \\
\text { Pyrimido[4,5-d] pyrimidine-2,4(1H,3H)-dione, 7-[(4-chlorophe- } \\
\text { nyl)imino]- } 6,7\end{array}$ & $\mathrm{C}_{21} \mathrm{H}_{18} \mathrm{CLN}_{5} \mathrm{O}_{2}$ & 407 & 3.14 \\
\hline 23 & 14.167 & $\begin{array}{l}\text { (+,-)-3.beta.-(acetyloxy)-3-ethynyl-1,2,3,4,4a.beta.,12a.beta.-hex- } \\
\text { ahydro-6,11-dihydroxy-7-methoxy-1.alpha.-(trimethylsilyl)-5,12- } \\
\text { naphthacenedione } \$ \$\end{array}$ & $\mathrm{C}_{26} \mathrm{H}_{28} \mathrm{O}_{7} \mathrm{~S}_{\mathrm{I}}$ & 480 & 5.67 \\
\hline 24 & 14.274 & $\begin{array}{l}\text { Silane, [1,3,5-benzenetriyltris (oxy)] tris[trimethyl- (CAS) Phlo- } \\
\text { roglucinol TriTMS } \$ 1,3,5 \text {-Trihydroxybenzene 1,3,5-Tritms } \$ \$ \\
\text { 1,3,5-Trihydroxybenzene 3TMS } \$ \$\end{array}$ & $\mathrm{C}_{15} \mathrm{H}_{30} \mathrm{O}_{3} \mathrm{~S}_{\mathrm{I}_{3}}$ & 342 & 2.76 \\
\hline 25 & 14.349 & $\begin{array}{l}\text { 1,2-Diphenyltetramethyldisilane \$\$ Disilane,1,1,2,2-tetrame- } \\
\text { thyl-1,2-diphenyl- \$\$ }\end{array}$ & $\mathrm{C}_{16} \mathrm{H}_{22} \mathrm{Si}_{2}$ & 270 & 4.98 \\
\hline 26 & 14.453 & $\begin{array}{l}\text { [Bis(trimethylsilyl)methyl]diphenylphosphine \$\$ Phosphine, } \\
\text { [bis(trimethylsilyl)methyl]diphenyl- (CAS) }\end{array}$ & $\mathrm{C}_{19} \mathrm{H}_{29} \mathrm{PS}_{\mathrm{I}}$ & 344 & $5 \cdot 59$ \\
\hline 27 & 14.588 & $\begin{array}{l}\text { 4H-1-Benzopyran-4-one, 2-(2,6-dimethoxy phenyl)-5,6-dimeth- } \\
\text { oxy- (CAS) Zapotin \$ 7187202001 Zapoti \$\$ Flavone, 2',5,6,6'-te- } \\
\text { tramethoxy- \$\$ }\end{array}$ & $\mathrm{C}_{19} \mathrm{H}_{18} \mathrm{O}_{6}$ & 342 & 2.46 \\
\hline 28 & 14.653 & 3,5,8-Trioxanonane, 4-methyl-6-oxiranyl-9-phenyl- \$\$ & $\mathrm{C}_{15} \mathrm{H}_{22} \mathrm{O}_{4}$ & 266 & 1.70 \\
\hline 29 & 14.708 & 2-Isopropylphenol-Trimethylsilyl-Ether \$\$ & $\mathrm{C}_{12} \mathrm{H}_{20} \mathrm{OS}_{\mathrm{I}}$ & 208 & 2.73 \\
\hline 30 & 14.856 & Anisuric acid, di-TMS $\$ \$$ & $\mathrm{C}_{16} \mathrm{H}_{27} \mathrm{NO}_{4} \mathrm{Si}_{2}$ & 353 & 1.52 \\
\hline 31 & 14.970 & Cyclohexa-1,4-Diene, 1,3,6-Tris(Trimethylsilyl)- \$\$ & $\mathrm{C}_{15} \mathrm{H}_{32} \mathrm{~S}_{\mathrm{I}_{3}}$ & 296 & 1.23 \\
\hline 32 & 15.007 & Propylparaben TMS Ether \$\$ & $\mathrm{C}_{13} \mathrm{H}_{20} \mathrm{O}_{3} \mathrm{~S}_{\mathrm{I}}$ & 252 & 0.73 \\
\hline 33 & 15.233 & $\begin{array}{l}\text { (Z)-1-[(1',1'-dimethylethyl)diphenylsilyl]-3-trimethylsilyloxyprop- } \\
\text { 1-ene \$\$ (Z)-3-[(1',1'-dimethylethyl)diphenylsilyl]-1-trimethylsily- } \\
\text { loxyprop-1-ene \$ Silane, [[3-[(1,1-dimethylethyl)diphenylsilyl] }\end{array}$ & $\mathrm{C}_{22} \mathrm{H}_{32} \mathrm{OS}_{\mathrm{I} 2}$ & 368 & 2.37 \\
\hline 34 & $15 \cdot 342$ & $\begin{array}{l}\text { Benzophenone, 2-(trimethylsiloxy)- (CAS) Trimethylsilyl ether of } \\
\text { o-hydroxybenzophenone } \$ \$\end{array}$ & $\mathrm{C}_{16} \mathrm{H}_{18} \mathrm{O}_{2} \mathrm{~S}_{\mathrm{I}}$ & 270 & 3.50 \\
\hline 35 & 15.434 & $\begin{array}{l}\text { Prosta-5,10,13-trien-1-oic acid, 15-[[(1,1-dimethylethyl)dimethylsi- } \\
\text { lyl] oxy]-9-oxo-, methyl ester, }(5 \mathrm{Z}, 13 \mathrm{E}, 15 \mathrm{~S}) \text { - \$\$ }\end{array}$ & $\mathrm{C}_{27} \mathrm{H}_{46} \mathrm{O}_{4} \mathrm{Si}$ & 462 & 2.19 \\
\hline 36 & $15 \cdot 508$ & $\begin{array}{l}\text { Benzoic acid, 2-[(trimethylsilyl)oxy]-, trimethylsilyl ester (CAS) } \\
\text { 2-Hydroxybenzoic Acid-DiTMS \$\$ Bistrimethylsilyl Salicylic Acid } \\
\text { \$ Trimethylsilyl OTrimethylsilylsalicylate }\end{array}$ & $\mathrm{C}_{13} \mathrm{H}_{22} \mathrm{O}_{3} \mathrm{~S}_{\mathrm{I} 2}$ & 282 & $5 \cdot 32$ \\
\hline 37 & 15.636 & Benzoic acid, 2-[(trimethylsilyl)oxy]-, trimethylsilyl & $\mathrm{C}_{13} \mathrm{H}_{22} \mathrm{O}_{3} \mathrm{Si}_{2}$ & 282 & 24.09 \\
\hline 38 & 15.880 & Nonamethyl, Phenyl-, Cyclopentasiloxane \$\$ & $\mathrm{C}_{15} \mathrm{H}_{32} \mathrm{O}_{5} \mathrm{~S}_{15}$ & 432 & 0.17 \\
\hline 39 & 21.767 & $\begin{array}{l}\text { 1-Trimethylsilyloxy-2-Trimethylsilylamino-3-(4'-Methoxyphenyl) } \\
\text { Propanone \$\$ }\end{array}$ & $\mathrm{C}_{16} \mathrm{H}_{29} \mathrm{NO}_{3} \mathrm{~S}_{\mathrm{I}_{2}}$ & 339 & 0.21 \\
\hline 40 & 17.027 & Nonamethyl, Phenyl-, Cyclopentasiloxane & $\mathrm{C}_{15} \mathrm{H}_{32} \mathrm{O}_{5} \mathrm{Si}_{5}$ & 432 & 6.10 \\
\hline
\end{tabular}

